\title{
Close linkage with the RET proto- oncogene and boundaries of deletion mutations in autosomal dominant Hirschsprung disease
}

Yin Luo', Isabella Ceccherini', Barbara Pasinl', Ivana Matera', M.Patrlzia Bicocchl', Virginia Barone', Renata BocclardI', Helena Kääriäinen², Daniel Weber ${ }^{3}$, Marcella Devoto',4 and Glovannl Romeo",

'Laboratory of Molecular Genetics, G Gaslini Institute, 16148 Genova, Quarto, Italy, 2Department of Medical Genetics, 00014 Unversity of Helsinila, Finland, ${ }^{2 D e p a r t m e n t}$ of Surgery, Kantonates Hosprtal of Wolhusen, 6110 Wolhusen, Switzerkand and "Department of Psychiatry. Columbia University, NY 10032 , USA

Received August 5, 1993; Revised and Accepted September 17, 1993

Tight IInkage with the RET proto-oncogene $(Z \max =3.41$ at $\theta=0.00)$, analysls of recombinants and detectlon of a familial microdeletion in a large pedigree restrict the mapplng of the Hirschsprung (HSCR) gene prevlously localized on proximal 10q. The molecular characterization of the famillal microdeletion and of 3 additional cytogenetically visible de novo deletions, Isolated In somatlc cell hybrids, Identify a smallest reglon of overlap of $250 \mathrm{~Kb}$. Thls contains the RET proto-oncogene where missense mutatlons causing multiple endocrine neoplasla type 2A (MEN 2A) phenotype were recently found. The pentagastrin test (which detects preclinical forms of MEN 2A or B) ls negative in adult HSCR patients with deletlons of the RET gene. This represents a good candldate for the search of mutations causing HSCR.

\section{INTRODUCTION}

Hirschsprung disease (HSCR, or congenital megacolon) is a neural crest cell disorder (neurocristopathy) characterized by the absence of intramural ganglion cells in the hindgut, often resulting in partial to complete intestinal obstruction during the first years of life. The disease has a complex genetic etiology and, among others, an autosomal dominant model of inheritance with incomplete penetrance was postulated $(1-4)$.

Cytogenetically detectable deletions, del 10(q11.2-21.2), were observed by us(5) and by Dr S.M.Huson (personal comm.) in two patients with sporadic occurrence of HSCR. These findings suggested the presence of a HSCR gene in the proximal long arm of chromosome 10 . Based on this hypothesis, we segregated the deleted and normal chromosomes 10 from one of the patients(5) into 2 distinct somatic cell hybrids(6) and mapped a series of chromosome 10 markers with respect to the deletion. Linkage analysis in $15 \mathrm{HSCR}$ pedigrees showing autosomal dominant inheritance indicated the interval between loci D10S208/D10S199 and D10S196/D10S220/D10S225, spanning $9.9 \mathrm{cM}$, as the most likely location of the gene( $(7)$. This finding was essentially confirmed by an accompanying paper (8). In order to refine this genetic mapping, we studied 5 pedigrees using 12 microsatellites localized in the region of interest. A familial microdeletion, revealed by this analysis, and 3 additional cytogenetically visible deletions allow now to define a smallest region of overlap for HSCR.

\section{RESULTS}

Linkage study and refined genetic map of HSCR

A total of 21 affected and 23 unaffected individuals were analysed in 5 HSCR pedigrees. The pattern of transmission of the disease is consistent with an autosomal dominant model of inheritance with incomplete penetrance $(2,3,7)$. Fig. 1 shows the haplotype reconstruction for 9 and 12 microsatellites respectively in 2 pedigrees. In the pedigree of fig.1A, ZNF22 showed a recombination with HSCR, while in the pedigree of fig. $1 \mathrm{~B}$, double recombinants were observed between marker AFM282ya9 and locus RBP3. These recombinations restricted the genetic mapping of the HSCR locus to a proximal $10 \mathrm{q}$ interval flanked by probes AFM282ya9 proximally and ZNF22 distally. A familial microdeletion involving the RET proto-oncogene and D10S141 was identified because of constitutional loss of heterozygosity in patients and asymptomatic obligate carriers of HSCR in the pedigree of fig. 1B. Table 1 shows the pairwise lod scores at different recombination fractions between the RET proto-oncogene and HSCR in the 5 pedigrees. The deleted allele was considered for this analysis as an additional null allele. Significant linkage between HSCR and RET was found $(\mathrm{Zmax}=3.41$ at $\Theta=0.00)$.

Detection of the familial microdeletion

A deletion involving locus D10S141 and the RET proto-oncogene segregates with HSCR in all patients and asymptomatic carriers

\footnotetext{
- To whom correspondence should be addressed
} 

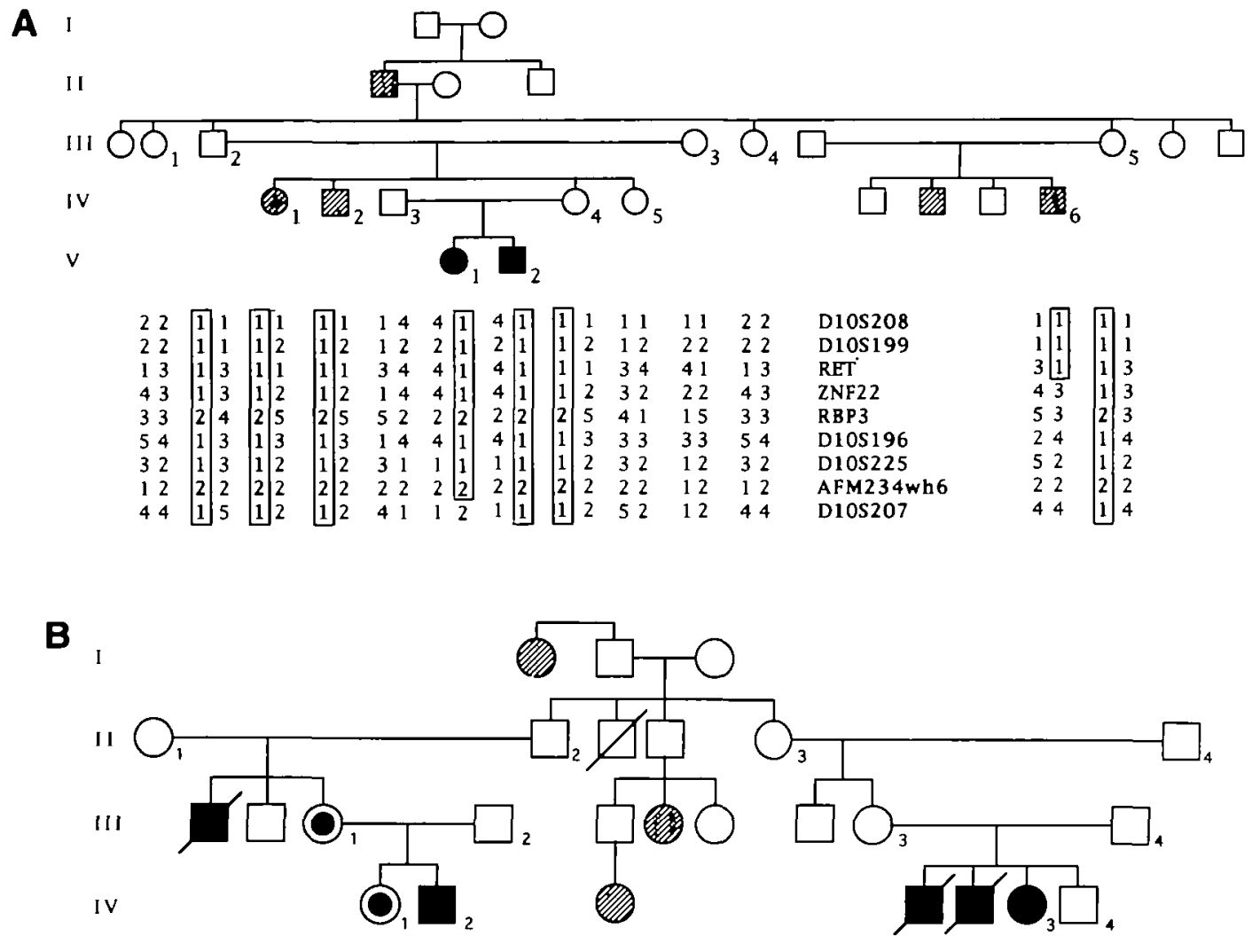

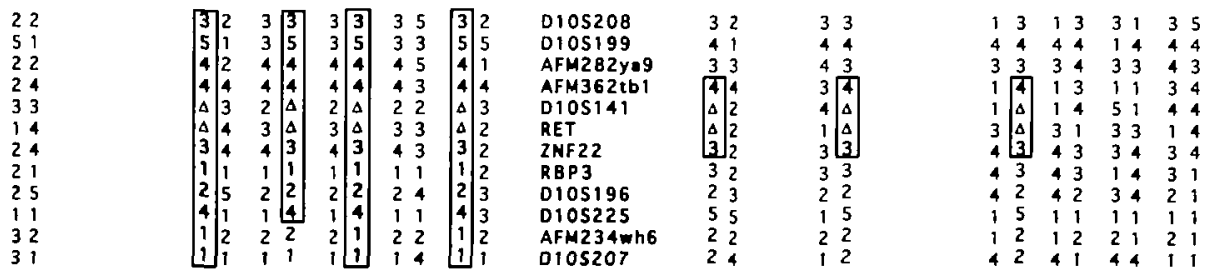

Figure 1. Haplotype reconstruction in 2 HSCR families.In the pedigrees, filled symbols $(\square, \bullet)$ represent long segment HSCR, half-filled symbols ( $\odot$ ) represent short segment HSCR, hatched symbols ( $(\mathbb{Z}, 0)$ represent a disease status not studied by histological examination but clinically documented as previously described(7). The markers are reported in their most likely order on chromosome 10: 10p-centromere-10q. $\Delta$ : deletion. Individuals numbered in each pedigree carry the haplotypes described in the corresponding positions of the lower part of the figure. Haplotypes which are concordant in all patients and obligate carriers are boxed. In pedigree A, the recombination drawn inside the haplotype of individual IV-6 (which maps HSCR proximal to ZNF22) might actually have occurred either in individual III-5 or IV-6. The same can be said for the recombinations observed in pedigree B, which might have occurred either in individual II-2 or II-3. Markers AFM183xg1 (D105208), AFM137xh4 (D10S199), AFM115xf2 (D10S196), AFM256yf9 (D10S225), AFM234wh6 (Gticthon, no D number available), AFM175xh10(D10S207)(16), RBP3(27) were previously mapped(7) with respect to the deletion of HSCR patient 1 (see table 2). New markers corresponding to loci D10S141, ZNF22(10) and microsatellite sTCL2 (corresponding to RET, derived from YAC 273E3 as an end probe)(14), AFM362tb1 (Génthon, no D mumber available) map inside the deletion, while AFM282ya9 (Génthon, no D number available) maps outside. This latter marker was physically mapped by us in the centromeric region using a panel of somatic cell hybrids (unpublished data).

of the pedigree of fig.1B. The presence of this microdeletion was confirmed by fluorescent in situ hybridization (FISH), utilizing as probes YACs 313F4, 273E3 and 344H4 (9). With each probe, only one spot was observed in the metaphases of a lymphoblastoid cell line from individual IV-1 in the pedigree of fig. 1B, while in a normal control two spots could be seen on the two chromosomes 10 (Fig. 2). In addition (Table 2), the same deletion was detected by cosmids cMEN367, from which the microsatellite D10S141 had been isolated (10), and cMEN284 (D10S137)(11,12), physically mapped in the same region, proximal to D10S141(our unpublished result).

\section{Deletion mapping of the HSCR gene}

The segregation in a somatic cell hybrid of the deleted chromosome 10 from our HSCR patient (corresponding to patient 1 of table 2) was previously described(6). Using the same approach, two additional hybrids retaining the deleted chromosome 10 respectively from patients 2 and 3 of table 2 were isolated. A cytogenetically visible deletion, del $10 \mathrm{q}(11.2-22.1)$, not associated with HSCR, had been previously isolated in a similar hybrid (corresponding to patient 4 of table 2)(13). Table 2 summarizes the characterization of the 4 somatic cell hybrids 
Table 1. Pairwise lod scores between HSCR and RET

\begin{tabular}{|c|c|c|c|c|c|c|c|}
\hline \multirow[b]{2}{*}{ Pedrgreo } & \multirow[b]{2}{*}{000} & \multicolumn{4}{|c|}{ Recombination Fractions ( $\theta$ ) } & \multirow[b]{2}{*}{0.30} & \multirow[b]{2}{*}{0.40} \\
\hline & & 0.01 & 0.05 & 010 & 020 & & \\
\hline 1 & 0.708 & 0.693 & 0.631 & 0552 & 0385 & 0.212 & 0.063 \\
\hline 2 & 1.603 & 1.571 & 1.442 & 1279 & 0.950 & 0.623 & 0.306 \\
\hline 3 & 0.373 & 0.364 & 0329 & 0285 & 0.198 & 0.115 & 0.046 \\
\hline 4 & 0.429 & 0.418 & 0.374 & 0318 & 0.206 & 0.104 & 0.028 \\
\hline 5 & 0.301 & 0.292 & 0258 & 0215 & 0134 & 0.064 & 0.017 \\
\hline Total & 3.414 & 3338 & 3034 & 2649 & 1872 & 1119 & 0461 \\
\hline
\end{tabular}

Pedigree 1, see Fig. 1A; Pedigree 2, see Fig. 1B; Pedigree 3, No. 8 of ref. 7; Pedigree 4 and 5 , nuclear families previously unreported;

for the presence of 17 different markers mapped in the proximal $10 \mathrm{q}$ region using PCR and FISH. The proximal boundary of the deletion present in patient 2 lies distal to D10S141, while the distal boundary of the familial microdeletion observed in the pedigree of fig. 1B (patient 3) lies proximal to yCME1-L, an STS previously reported(14). The smallest region of overlap thus defined by the latter 2 deletions spans approximately $250 \mathrm{~Kb}$ as deduced from a physical map of the region obtained from YAC clones $(9,14)$. The proximal breakpoint from the patient not affected with HSCR (patient 4) is distal to RBP3 and is therefore located outside the smallest region of overlap. Additional evidence was obtained by FISH using YACs $273 \mathrm{E} 3$ and $344 \mathrm{H} 4$ and different cosmids as probes (Table 2). The deletion of YAC $344 \mathrm{H} 4$ in Hy8018.27A was confirmed by FISH performed on lymphoblasts from the same patient(patient 2). On the other hand, YAC 273E3 hybridized with both the deleted and the normal chromosomes 10 carried by lymphoblasts from patient 2 (Fig. 2). This is in agreement with the distal localization of the proximal breakpoint present in this patient who retains most of the human DNA material contained in the YAC 273E3.

Pentagastrin tests in individuals with deletions of the 10q11.2 region

Since the RET proto-oncogene which corresponds to the MEN $2 \mathrm{~A}$ gene( 15 ) lies within the $250 \mathrm{~Kb}$ region containing the HSCR gene, we tested whether individuals showing the familial microdeletions (Fig. 1B) had any signs of MEN 2A. The family history was negative for MEN 2 and a pentagastrin test was performed in individuals II-2 (58 years old) and III-1 (29 years old). The plasma calcitonin concentrations were within normal limits both under baseline conditions and after pentagastrin stimulation (data not shown).

\section{DISCUSSION}

The new linkage data from the present work narrow the previous genetic mapping from an interval of $9.9 \mathrm{cM}(7)$ to not more than $2.7 \mathrm{cM}(10,16)$, flanked by marker AFM282ya9 and locus ZNF22. Tight linkage ( $\mathrm{Zmax}=3.41$ at $\theta=0.00$ ) of HSCR with marker STCL2, which maps about $60 \mathrm{~Kb}$ distal to the $3^{\prime}$ end of the RET proto-oncogene(14), is now identified. This gene is flanked by microsatellites STCL2 distally and D10S141 proximally $(9,14)$. Hemizygosity for sTCL2 and D10S141, confirmed by FISH, indicates that the RET proto-oncogene is deleted in affected members as well as in the asymptomatic obligate carriers of the gene in the pedigree of fig.1B. In addition, physical characterization of the three deletions associated with HSCR, isolated in 3 different hybrids (Table 2), allowed us to
Table 2. Retention (+)and loss ( - ) of DNA markers in 4 somatic cell hybrids carrying deletions of proximal $10 \mathrm{q}$

\begin{tabular}{|c|c|c|c|c|c|c|c|c|}
\hline & $\mathrm{Kb}$ & $\begin{array}{l}\text { DNA } \\
\text { MARKERS }\end{array}$ & 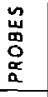 & 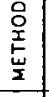 & $\begin{array}{r}\text { DELETEO } \\
1 \\
\end{array}$ & $\begin{array}{l}\text { CHROMOSOMES } \\
2 \\
\end{array}$ & $\begin{array}{c}10 \text { FROM } \\
3 \\
\end{array}$ & $\begin{array}{l}\text { PATIENTS } \\
4 \\
\end{array}$ \\
\hline & cen & & & & & & & \\
\hline$\Rightarrow$ & 10 & $214 \mathrm{H} 10 \mathrm{~T}$ & a & $\mathbf{P}$ & + & + & - & + \\
\hline :2 & [ & YWME 3 I-R & $a$ & $\mathbf{P}$ & + & + & - & + \\
\hline & 240 & D10S137 & e & $\mathrm{F}$ & - & + & - & nd \\
\hline & 150 & 0105141 & $c, e$ & F.P & - & + & - & + \\
\hline ज़ & 60 & RET & b & $\mathrm{P}$ & - & - & - & + \\
\hline & & STCL-2 & c & $\mathrm{P}$ & - & - & - & nd \\
\hline & 43 & YCME 1-L & a & $P$ & - & - & + & nd \\
\hline & 160 & YWME3 1-L & a & $P$ & nd & nd & + & nd \\
\hline & 20 & YWMEZ B-R & a & $\mathbf{P}$ & - & - & + & nd \\
\hline $\begin{array}{l}C M \\
22\end{array}$ & & D10S94 & d & $P$ & - & - & + & + \\
\hline 1.5 & & ZNF22 & $b$ & $P$ & - & - & nd & + \\
\hline 3.3 & & RBP 3 & b & $\mathrm{P}$ & - & - & nd & + \\
\hline & & D10S196 & c & $P$ & - & - & + & - \\
\hline 3.4 & & AFM263yd5 & c & P & - & - & nd & - \\
\hline 66 & & AFM205tg11 & c & $\mathrm{P}$ & - & - & nd & - \\
\hline 8.0 & & AFM234wh6 & c & $\mathbf{P}$ & - & - & + & - \\
\hline & qter & 0105210 & c & $\mathrm{P}$ & + & + & + & - \\
\hline
\end{tabular}

Probes a: STSs derived from the ends of YAC clones belonging to two recently described contigs $(9,14)$; b: expressed sequences $(28-31)$; c: microsatellites $(10,14,16)$; d: amplifiable sequence containing a Pvu II polymorphic restriction site(32); e: cosmid clones already described $(11,12)$; nd: not determined. Patients 1: reported in ref.5,6; 2: observed by Dr. S. M. Huson (unpublishod data); 3: individual IV-1 of fig.1B; 4: reported in ref. 13 (not affected with HSCR). The deleted chromosomes observed in these 4 patients are retained respectively in Hy185.0, Hy8018.27A, Hy8016.38 and CZxCHOK1. All markers are listed in their most likely order from centromere to quer as already raported( $(9-12,14,16)$, with the exception of the microsatellites distal to RBP3, whose reciprocal order is tentatively defined. The physical $(\mathrm{Kb})$ and genetic $(\mathrm{cM})$ distances between markers deducod from the literature $(9,10,14,16)$ are indicated respectively in the upper and lower part of the table. F: studied by FISH in lymphoblastoid cell lines; P: tested by PCR amplification of DNA from somatic cell hybrids. In addition, YAC 273E3 showed no signal by FISH (Fig. 2) on the deleted chromosomes 10 from lymphoblasts of patient 1 and of patient 3 (parental cell lines of Hy185.0 and Hy8016.38 respectively). The absence of signal with YAC 273E3 in patient 3 is in apparent contrast with the observation that Hy8016.38 is positive for yCME1-L, located inside this YAC. This is explained by the localization of the former STS in a small terminal portion of the YAC. A clear fluorescent signal (Fig. 2)was present instead in both the normal and the deleted chromosome 10 from lymphoblasts of patient 2 (parental cell line of Hy8018.27A).

define a smallest region of overlap between D10S141 and yCME1-L. This result restricts the HSCR gene to a region of approximately $250 \mathrm{~Kb}$. The RET proto-oncogene $(17,18)$, whose genomic length is at least $35 \mathrm{~Kb}$ (B.Pasini et al., in preparation), is the only gene already mapped in this region and represents therefore a potential candidate for HSCR. Recently, the same 
A

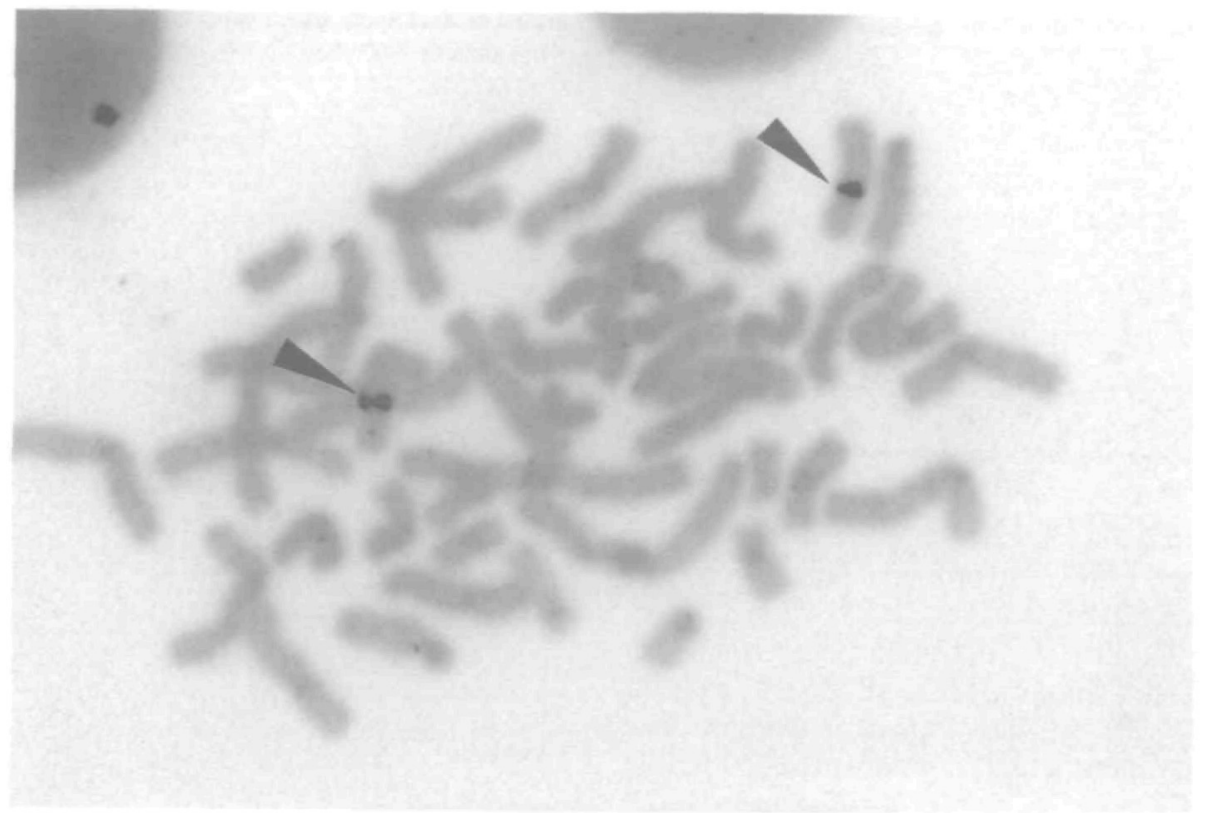

B

Figure 2. Fluorescent in situ hybridization of lymphoblastoid cell lines from 2 HSCR patients showing deletion mutations. A: Patient 2 of table 2. Both chromosome 10 (identifed on the same slide by DAPI Q banding) show a clear fluorescent signal using YAC 273E3 as probe (see arrows); B: Patient 3 of table 2 (TV-1 of the pedigree of fig.1B). Only 1 chromosome 10 (identified again by DAPI Q banding) hybridizes YAC 273E3 (see arrow).

gene has been shown to carry missense mutations affecting different cysteine residues at the boundary of the extracellular and transmembrane domains in patients with multiple endocrine neoplasia type 2A (MEN 2A)(15,19).

The RET proto-oncogene may play an important role in the development of the enteric nervous system(20,21). A recent study of a transgenic mouse strain in which both alleles of the RET proto-oncogene were 'knocked out', demonstrates severe kidney malformations and complete aganglionosis of the whole intestine (Dr V.Pachnis, personal comm.). In the present work, a deletion involving the RET proto-oncogene is inherited as a dominant mutation which causes HSCR in the pedigree of fig. 1B. This deletion, as well as 2 de novo deletions in sporadic HSCR patients, must cause a quantitative decrease of the RET gene product, which might result in the HSCR phenotype. In the few large pedigrees $(22,23)$ where MEN $2 A$ or $B$ are found associated with HSCR, the latter disorder is less frequent than MEN 2, indicating that only in a minority of patients the same mutation gives origin to HSCR, in addition to MEN 2, possibly because of the interaction with a second, modifier gene. However the negative results obtained in carriers of the familial microdeletion (patient III-1 and her unaffected father in the pedigree of fig.1B) 
after pentagastrin stimulation (which is a reliable test for the detection of preclinical forms of MEN 2A or B) exclude the presence in them of any form of medullary thyroid hyperplasia. We conclude therefore that deletion mutations of the RET protooncogene do not represent a sufficient condition for the development of MEN 2A, whose reported point mutations might represent instead the first example of a dominantly acting oncogenic mechanism as the initiating event in human hereditary neoplasia(15). This observation is consistent with the absence of allele loss reported for $10 \mathrm{q}$ in medullary thyroid carcinoma and pheochromocytoma $(24,25)$. On the other hand, it is somewhat surprising that the 3 deletions causing HSCR characterized in the present work are not associated with other congenital anomalies, in spite of their extent (see table 2).

Allelic mutations causing different disease phenotypes have been documented for Duchenne and Becker Muscular Dystrophy (MIM No. 310200), for Cystic Fibrosis (MIM No. 219700) and Congenital Bilateral Absence of Vas Deferens(26), for Spinal Bulbar Muscular Atrophy (Kennedy disease, MIM No. 313200) and Testicular Feminization (MIM No. 313700), and for a few other disorders. Our hypothesis of phenotypic diversity between HSCR and MEN2A due to multiple alleles (e.g.: gene deletions or specific missense mutations, respectively) is therefore supported by well established examples.

\section{MATERIALS AND METHODS}

\section{Subreghonal assignment of markers and deletion mapping}

The sequences of all microsatellites have been published previously $(10,14,16,27)$. Their order and genetic distances were already established in CEPH families. Somatic cell hybrids retaining the deleted chromosome 10 were obtained as previously described(6). The subregional localization of the markers used in linkage analyses was carried out by PCR amplification of the DNAs from the two somatic hybrids retaining the deleted (Hy 185.0) and the normal chromosomes 10 (Hy179.Q) from one of the deleted patients $(6,7)$. Other probes used to test the presence of DNA markers in the 4 hybrids retaining the deleted chromosome 10 are defined elsewhere $(9-12,14,16,27-32)$. Standard PCR reactions were performed for all microsatellites, expressed sequences and STSs using DNA or cell lysate of the human-rodent cell hybrids.

\section{Genotyping}

Genomic DNA was purified either from blood samples or from established lymphoblastoid cell lines by conventional methods. For each pair of primers, the one having higher melting temperature was labelled with $\gamma^{32}$ P-dATP by T4 polynucleotide kinase. Standard PCR reactions were carried out with $0.4 \mu \mathrm{M}$ unlabeled primer and $0.1 \mu \mathrm{M}$ of end-labelled primer in a total volume of $15 \mu$ or $25 \mu \mathrm{l}$ with $1-1.5$ units of Taq polymerase. $100-200 \mu \mathrm{g}$ of template DNAs were initially denatured at $95^{\circ} \mathrm{C}$ for $5 \mathrm{~min}, 30$ cycles of amplification were performed by denaturing at $94^{\circ} \mathrm{C}$ for $40 \mathrm{sec}$, annealing at $55^{\circ} \mathrm{C}$ (AFM183xgl and RBP3 at $57^{\circ} \mathrm{C}$ ) for $40 \mathrm{sec}$, elongating at $72^{\circ} \mathrm{C}$ for $1 \mathrm{~min}$, followed by a final step of $72^{\circ} \mathrm{C}$ for $7 \mathrm{~min}$. 2-3 $\mu \mathrm{l}$ of PCR products were loaded on $6 \%$ polyacrylamide sequencing gel containing $7 \mathrm{M}$ urea.

\section{Linkage study}

Members of the 5 pedigrees were classified as affected with long segment or short segment HSCR according to the criteria previously reported(7). Pairwise linkage analysis was performed using the MLINK option(33) of the computer program Linkage package (version 5.1), under the assumption of a sex-modified, incompletely penetrant, autosomal dominant model. Estimates for gene frequency and for differential penecrance in males and fermales were those already reported(T). The frequencies for different alteles of sTCL2 (RET) were assumed to be equivalent for 6 alleles $(0.167$ each).

\section{Fluorescent in situ hybridization}

Cosmid and YAC probes were labeled by nick translation (Boehringer) using biotin-16-dUTP. Metaphase chromosomes of the lymphoblastoid cell lines were prepared by routine methods. Hybridization and washing conditions were as described $(34,35)$. The signals were amptified once and the slides were stained with propidium iodide and DAPI. At least $\mathbf{5 0}$ metaphases were scored for each experiment and all were concordant with the result reported. A normal lymphoblastoid cell line was included in each hybridization as control.

\section{ACKNOWLEDGEMENTS}

We gratefully acknowledge Prof. A.Schinzel, Dr U.G.Stauffer (Zurich) and Dr. C.Monteiro (Lisboa) for providing material from nuclear families 4 and 5 reported in table 1, Dr S.M.Huson and Prof. B.A.J.Ponder for providing the cell line Lb8018, Dr R.A.Norum for providing hybrid CZxCHOK1, Dr D.Le Paslier (CEPH, Paris) for providing YACs 273E3,313F4 and 344H4, Dr Y.Nakamura for providing cosmids cMEN367 and cMEN284, Dr J.Weissenbech for providing information on Gtnethon microsatellites. This work was supported by grants from the EEC(PL910027), the Italian CNR (Progetto Finalizzato Ingegneria Genetica), the Italian Ministry of Health, the Italian Telethon and the A.I.R.C.. Y.L. and B.P. were the recipients of a fellowship from ICGEB (Trieste) and from Associazione Malattie Rare 'Mauro Baschirotto' and Cassa di Risparmio di VE, VI, BL, AN, respectively.

\section{ABBREVIATIONS}

$\begin{array}{ll}\text { HSCR } & \text { Hirschsprung disease } \\ \text { MEN2A } & \text { multiple endocrine neoplasia type 2A } \\ \text { MEN2B } & \text { multiple endocrine neoplasia type 2B } \\ \text { MEN2 } & \text { multiple endocrine neoolasia type 2 } \\ \text { STS } & \text { sequence tagged site } \\ \text { FISH } & \text { fluorescent in sin hybridization }\end{array}$

\section{REFERENCES}

1. Kaiser,G. and Bettex,M. (1982) In Holschneider,A.M. (ed.), Hirschspnung's Disease. Hippokrates Verlag, Stuttgart/Thieme-Strattan, Inc., New York, pp. $43-53$.

2. Garver,K.L., Law,J.C. and Garver,B. (1985) Clin. Genet. 28, 503-508.

3. Badner,J.A., Sieber, W.K., Garver,K.L. and Chakravarti,A. (1990) Am. J. Hum. Genet. 46, 568-580.

4. Bedner,J.A. and Chakravarti,A. (1990) Am. J. Med. Genet. 35, 100-104.

5. Martucciello,G., Bicocchi,M.P., Dodero,P., Lerone,M., Cirillo,M.S., Puliti,A., Gimelli,G., Romeo, G. and Jasonmi, V. (1992) Pediatr. Surg. Intern. 7, 308-310.

6. Puliti,A., Covone,A.E., Bicocchi,M.P., Bolino,A., Lerone,M., Martucciello,G., Jasonni,V. and Romeo,G. (1993) Cytogenet. Cell Genet. 63, $102-106$.

7. Lyonnet,S., Bolino,A., Pelet,A., Abel,L., Nihoul-Fekete,C., Briard,M.L., Siu,V.M., Käåriäinen ${ }^{2}$,H., Martucciello,G., Lerone,M., Puliti,A., Yin,L., Weissenbach,J., Devoto,M., Munnich,A. and Romeo,G. (1993) Nature Genet. 4, 346-350.

8. Angrist,M., Kauffman,E., Slaugenhaupt,S.A., Matise,T.C., Puffenberger,E.G., Washington,S.S., Lipson,A., Cass,D.T., Reyna,T., Weeks,D.E., Sieber,W. and Chakravarti,A. (1993) Nature Genet. 4, 351-356.

9. Mote,S.E., Mulligan,L.M., Healey,C.S., Ponder,B.A.J. and Tunnadiffe,A. (1992) Hum. Mol. Genet. 2, 247-252.

10. Gardner,E., Papi,L., Easton,D.F., Cummings,T., Jackson,C.E., Kaplan,M., Love,D.R., Mole,S.E., Moore,J.K., Mulligan,L.M., Norum,R.A., Ponder,M.A., Reichlin,S., Stall,G., Telenius,H., Telenius-Berg, M., Tunnacliffe, A. and Ponder,B.A.J. (1993) Hum. Mol. Genet. 2, 241-246.

11. Tokino,T., Takigucti,S., Tanigami,A., Bragg,T., Jones, C. and Nakamura, Y. (1992) Genomics 12, 401-402.

12. Mole,S.E., Jackson,M.S., Tokino,T., Nakarmura,Y. and Ponder,B.A.J. (1993) Genomics 15, 457-458

13. Nonum,R.A., Worsham,M.J., Van Dyke,D.L., Babu,V.R., and Jackson,C.E. (1988) Am. J. Hum. Genet. 43, A154.

14. Lairmore,T.C., Dou,S., Howe,J.R., Chi,D., Carlson,K., Velle,R., Mishra,S.K., Wells,S.A.,Jr. and Donis-Keller,H. (1993) Proc. Natl. Acad. Sci. U.S.A. $90,492-496$.

15. Mulligan,L.M., Kwok,J.B.J., Healey,C.S., Elsdon,M.J., Eng,C., Gardner,E., Love,D.R., Mole,S.E., Moore,J.K., Papi,L., Ponder,M.A., Telenius,H., Tunnacliffe,A. and Ponder,B.A.J. (1993) Nature 363, 458-460.

16. Weissenbach,J., Gyapay,G., Dï,C., Vignal,A., Morissette,J., Millasseau,P., Vaysseix,G. and Lathrop,M. (1992) Nature 359, 794-801.

17. Takahashi,M., Ritz,J. and Cooper,G.M. (1985) Cell 42, 581-588.

18. Schneider,R. (1992) TIBS 17, 468-469.

19. Donis-Keller,H., Dou,S., Chi,D., Carison,K.M., Toshima,K., Lairmore, T.C., Bowe,J.R., Moley,J.F., Goodfellow,P. and Wells,S.A.,Jr (1993) Hum. Mol. Genet. 2, 851-856. 
1808 Human Molecular Genetics, 1993, Vol. 2, No. 11

20. Kapur,R.P., Yost,C. and Palmiter,R.D. (1992) Development 116,167-179.

21. Cass,D,T., Zhang,A.L. and Morthorpe,J. (1992) J. Pediatr. Surg. 27, 351-356.

22. Verdy,M., Weber,A.M., Roy,C.C., Morin,C.L., Cadotte,M. and Brochu,P. (1982) J. Pediatr. Gastoenterol. Nutr. 1, 603-607.

23. Frilling,A., Becker,H. and Roeher,H.D. (1992) Henry Ford Hosp. Med. J. 40, 253-255.

24. Landsvater,R.M., Mathew,C.G.P., Smith,B.A., Marcus,E.M., Te Meerman,G.J., Lips,C.J.M., Geerdink,R.A., Nakamura,Y., Ponder,B.A.J. and Buys,C.H.C.M. (1989) Genomics 4, 246-250.

25. Nelkin,B.D., Nakamura,Y., White,R.W., De Bustros,A.C., Herman,J., Wells,S.A. Jr. and Baylin,S.B. (1989) Cancer Res. 49, 4114-4119.

26. Rigot,J.M., Lafitte,J.J., Dumur,V., Gervais,R., Manouvrier,S., Biserte,J., Mazeman,E. and Roussel,P. (1991) New Engl. J. Med. 325, 64-66.

27. Papi,L., Tunnacliffe,A. and Ponder,B.A.J. (1993) Hum. Mol. Genet. 1, 450.

28. Rosseau-Merck,M.F., Tunnacliffe,A., Berger,R., Ponder,B.A.J. and Thiesen,H.J. (1992) Genomics 13, 845-848.

29. Ishizaka, Y., Itoh,F., Tahira, T., Ikeda,I., Sugimura, T., Tucker,J., Fertitta,A., Carraní,A.V. and Nagao,M. (1989) Oncogene 4, 1519-1521.

30. Mathew,C.G.P., Chin,K.S., Easton,D.F., Thorpe,K., Carter,C., Liou,G.I., Fong,S.L., Bridges,C.D.B., Haak, H., Nieuwenhuijzen Kruseman,A.C., Schifters,S., Hansen,H.H., Telenius,H., Telenius-Berg,M.and Ponder,B.A.J. (1987) Nature 328, 527-528.

31. Simpson,N.E., Kidd,K.K., Goodfellow,P.J., McDermid,H., Myers,S., Kidd,J.R., Jackson,C.E., Duncan,A.M.V., Farrer,L.A., Brasch,K., Castiglionell,C., Genel,M., Gertner,J., Greenberg,C.R., Gusella,J.F., Holden,J.J.A. and White,B.N., (1987) Nature 328, 528-530.

32. Brooks-Wilson,A.R. Smailus,D., Gilchrist,D and Goodfellow,P.J. (1992) Genomics 13, 233-234.

33. Lathrop,G.M. and Lalouel,J.M. (1984) Am. J. Hum. Genet. 36, 460-465.

34. Lichter,P., Boyle,A.L., Gremer,T. and Ward,D.C. (1991) Genet. Anal. Techn. Appt. 8, 24-35.

35. Wada,M., Little,R.D., Abidi,F., Porta,G., Labella,T., Cooper,T., Valle,G.D., D'Urso,M., and Schlessinger,D. (1990) Am. J. Hum. Genet. 46, $95-106$. 